\title{
El análisis de libros de texto: una estrategia metodológica en la formación de los profesionales de la educación
}

\section{Analyzing textbooks: a methodological strategy in the initial training of education professionals}

\author{
Gloria BRAGA BLANCO y José Luis BELVER DOMÍNGUEZ \\ Universidad de Oviedo
}

Recibido: Junio 2014

Evaluado: Octubre 2014

Aceptado: Octubre 2014

\section{Resumen}

A pesar de la progresiva introducción de nuevos recursos en las aulas fruto del desarrollo de las TICs, el libro de texto sigue siendo uno de los materiales más utilizado y cuyo protagonismo en la configuración de la práctica escolar ha sido decisivo, por lo que debe ocupar nuestra atención en la formación inicial de los profesionales de la educación.

Durante los cursos académicos 2012-13 y 13-14, hemos realizado en el marco de la asignatura de Análisis y diseño de materiales para la educación y la formación del tercer curso del grado de Pedagogía de la Universidad de Oviedo una práctica formativa de análisis de libros de texto escolares que nos ha permitido analizar contextualizadamente y desde una perspectiva teóricopráctica, cuestiones tales como: papel del profesorado en el desarrollo e innovación del currículum, papel de las editoriales en la interpretación del currículum oficial, análisis de tareas y mensajes en los manuales escolares, criterios para juzgar la calidad didáctica de los materiales, etc. El análisis cualitativo de treinta informes desarrollados por 120 estudiantes sobre diferentes libros de texto nos ha permitido identificar sus principales fortalezas y debilidades en varias dimensiones (aspectos formales, metodología, mensajes, implicaciones para la profesionalidad docente) y nos permite concluir que se trata de una experiencia formativa relevante en la formación inicial de cualquier profesional de la educación.

Palabras clave: enseñanza superior, material didáctico, libros de texto, práctica pedagógica.

\begin{abstract}
Textbook remains the most used resource in the classroom and its role has been decisive in shaping school practice as we know it today. Because of that its study is exceptionally useful in the initial training of education professionals.

During two academic years (2012-13 and 13-14), we have implemented a formative task of analyzing textbooks in the subject of "Analysis and design of materials for education and formation" in third course of the degree of Pedagogy in the University of Oviedo. It has allowed us to analyze from a theoretical - practical perspective, questions such as: paper of teachers in the development and innovation of curriculum, paper of publishing companies in the


interpretation of official curriculum, analysis of pedagogical tasks and messages, criteria to judge the didactic quality of materials and so on. The qualitative analysis of thirty reports written by 120 students about textbooks, has allowed us to identify their main strengths and weaknesses in several aspects (formal aspects, methodology, messages and implications for teaching profession) and allows us to conclude that it is a relevant formative experience in the initial training of any education professional.

Keywords: higher education, teaching materials, textbooks, teaching practice.

Desde una perspectiva histórica se constata cómo el origen del libro de texto, tal y como hoy lo conocemos, está ligado al desarrollo y expansión de los sistemas nacionales de educación, en concreto, a la implantación de los modelos de enseñanza simultánea necesarios en un sistema generalizado de instrucción pública primaria (Escolano, 1997). Fue dentro de los sistemas nacionales de educación donde el libro de texto se constituyó en un instrumento regulador del diseño y desarrollo del currículum escolar. Y es en el contexto discursivo de la modernidad en el que se convirtió en un "proyecto cultural pretendidamente totalizador, que explique el mundo, lo signifique e instituya de razón ilustrada. Una enciclopedia” (Martínez Bonafé y Rodríguez Rodríguez, 2010: 246). Por tanto, además de permitir dar forma a las nuevas prácticas curriculares, el libro de texto fue pronto percibido por el nuevo orden liberal-burgués como un instrumento adecuado para transmitir a los niños los valores del nuevo ciudadano. Por ello tanto los contenidos culturales, como el lenguaje y las imágenes de los textos escolares han ocupado la atención preferente de numerosas investigaciones que se han preocupado por desvelar la ideología que subyace a los mismos. Por ello también los libros de texto han sido históricamente un producto cultural controlado por los poderes políticos que han regulado su uso (Beas, 1999).

Ya desde su surgimiento el libro escolar se ha desarrollado como producto editorial peculiar y diferenciado (Escolano, 1997; Gimeno, 2012). Algunos se han referido a él como género literario de no ficción condicionado por las finalidades instruccionales a las que sirve (Borre Johnsen, 1996; Selander, 1995), carente de ironías, que sólo hace referencia al mundo real, con instrucciones que regulan su lectura y con peculiares modos de maquetación, composición, edición, encuadernación, tipografía y uso de las ilustraciones, características que además se han mostrado especialmente resistentes a la innovación a través del tiempo (Martínez Bonafé y Rodríguez Rodríguez, 2010).

El libro de texto se ha configurado como una invariante de la escuela, como un material estable, de hecho el material pedagógico de más larga duración en la historia de la escuela, aunque sujeto a modificaciones y transformaciones que hacen que se haya diversificado en una gran variedad de modelos que van desde las clásicas fichas o materiales autoinstructivos pasando por la incorporación de guías didácticas o libros del profesor -que describen el sistema curricular en el que insertar el libro del alumno-, paquetes didácticos que suelen recoger un conjunto variado de materiales como láminas, libros, cuadernos, material manipulativo y audiovisual, llegando a los libros en soporte digital recientemente disponibles on-line. En los últimos tiempos el crecimiento de los libros digitales ha sido significativo, representando ya en torno al 25\% de los editados en papel para uso de los estudiantes (Asociación Nacional de 
Editores de Libros y Material de Enseñanza-ANELE, 2013). Incluyen acceso a recursos interactivos digitales, propuestas didácticas para el profesorado, contenidos complementarios, herramientas de subrayado, dibujo..., están diseñados para adaptarse a las necesidades de la pizarra digital y suelen incluir actividades para los estudiantes interactivas y autocorregibles.

Debemos ser conscientes, sin embargo, de que la irrupción en el mundo de las publicaciones didácticas de la informática no siempre ha significado rupturas significativas en relación a los diseños textuales tradicionales (Escolano, 1998). Si analizamos las versiones digitales de los libros de las principales editoriales nos encontramos que, aunque algunos contienen animaciones sencillas de determinados procesos complejos de explicar verbalmente, es habitual que los "interfaces" de comunicación persona-máquina estén alejados de haber sido pensados desde puntos de vista didácticos o estéticos, reproduciendo el formato y la propuesta metodológica de la edición impresa. La mayoría no están aprovechando suficientemente lo que el nuevo entorno puede aportar de realmente novedoso en educación: las capacidades multimedia, las simulaciones y la relación hipertextual de la información.

\section{El papel de los libros de texto en nuestras aulas}

Para entender su papel predominante en las escuelas, es necesario entender las funciones que realizan los libros de texto en el marco del desarrollo curricular (Puelles, 2000; Torres, 1994):

- Realizan una determinada selección cultural. Los libros de texto transmiten una determinada visión de la realidad, representando el saber oficial. Se presentan como una fuente de información "legítima" (contienen la información necesaria para aprobar) transmitiendo valores de forma manifiesta o latente, contribuyendo a la inculturación de las nuevas generaciones. Así las investigaciones sobre libros de historia nos señalan cómo sus narrativas evolucionan en función de la necesidad de construir una nueva perspectiva nacional o de otra índole en una determinada sociedad y momento histórico dado (Terra, 2014). En relación a esta función el Estado ha controlado históricamente -en ocasiones censurado- este recurso didáctico. En nuestro país la primera Ley educativa en la que se recoge que la edición y adopción de libros de texto no requiere ningún tipo de autorización previa de la administración educativa fue la LOCE en el 2002. La LOE recogió la misma disposición (Disposición adicional cuarta) en 2006, sin modificar por la recientemente aprobada LOMCE.

- Son un producto de consumo. Son un producto de consumo que es necesario analizar a la luz de los procesos de producción y comercialización de los mismos (Pérez Sabater, 2001, Watt, 2007). Según los datos de la ANELE (2013) (asociación que reúne al 90\% del sector editorial), a pesar de la crisis y de los programas de préstamos, se facturaron en el curso 11-12 un total de 803 millones de euros a nivel estatal. Dos grandes empresas -Anaya y Santillana- se disputan el consumo mayoritario y controlan casi el 50\% de la producción total (Martínez Bonafé y Rodríguez Rodríguez, 2010: 252). La otra gran empresa de nuestro 
mundo editorial junto con Anaya y Santillana es S.M. (Federación de Gremios de Editores de España, 2012, citado en González y Montero, 2013: 94).

A las funciones anteriormente citadas hay que añadir la más relevante desde el punto de vista de la formación inicial y que, por tanto, es la que aquí más nos interesa:

- Se convierten en el currículum real. El libro de texto se ha convertido en un producto escolar específico en el que se materializa el currículo en todas sus dimensiones (Escolano, 1997). Si bien la lógica nos debería llevar a considerarlos exclusivamente como mediadores del aprendizaje de los alumnos, entre otros muchos, la realidad es que históricamente se han configurado también como la más importante propuesta curricular que interpreta y concreta el currículum oficial para el profesorado.

Las consecuencias son evidentes: se desprofesionaliza al profesorado ejerciendo el control curricular desde instancias ajenas a los propios centros educativos (Apple, 1993; Martínez Bonafé, 2002) y se uniformiza el aprendizaje ofreciendo una única visión de los mensajes culturales, teniendo solamente en mente un alumno estándar y desconsiderando las diferencias culturales y sociales de los diversos grupos de estudiantes (Martínez Bonafé y Rodríguez Rodríguez, 2010). Sin embargo las profesoras y profesores siguen utilizando los libros de texto. El 81,3\% de los profesores/as reconocen emplearlo bastante o mucho. El 71,9\% de los padres lo considera imprescindible como recurso didáctico (incluso por encima de internet) (ANELE, 2013). Es necesario, pues, que los futuros profesionales entiendan el papel que cumplen en la práctica escolar y por qué se han convertido en el material didáctico por excelencia. Quizás la solución no está en satanizarlos, sino en formar al profesorado en su análisis así como en el diseño de materiales alternativos o complementarios al libro de texto. Para ello hoy en día disponemos de un amplísimo abanico de materiales curriculares en la red (no siempre fácilmente localizables) y de todo un campo de estudio y debate relacionado con su diseño, producción, selección, evaluación y uso que ya ocupa un espacio propio dentro de la investigación pedagógica nacional (Beas, 2013; Blanco, 2000, 2001, 2008; Martínez Bonafé, 2002, 2007, 2008; Martínez Bonafé y Rodríguez Rodríguez, 2010; Torres, 1991, 1994, 1995) o internacional, a través sobre todo del trabajo de la Asociación Internacional IARTEM (International Association for Research on textbooks and Educational Media) (Figueiredo y otros, 2013; Mazaikiene y otros, 2011; Rodríguez y otros,2009).

\section{Criterios para construir un modelo de análisis de libros de texto en la formación inicial de profesionales de la educación.}

El libro de texto escolar es un material que presenta unas características peculiares: es un mediador del aprendizaje del estudiante, pero también se ha configurado como el material curricular de uso preferente del profesorado. Por ello el análisis del libro de texto ofrece enormes posibilidades en la formación inicial de profesionales de la educación. 
Como cualquier material dirigido a mediar en el aprendizaje de los estudiantes el libro de texto debe ser juzgado por la calidad didáctica de sus aspectos formales. Debemos analizar la calidad didáctica de las imágenes y su relación con los mensajes textuales. Las ilustraciones se han estudiado desde una perspectiva técnica (en cuanto a su grado de realismo, calidad estética, valor ilustrador) y no han faltado las críticas que señalan su baja calidad: gráficos a menudo mal elaborados, esquemas incompletos, croquis incomprensibles, etc. La investigación también se ha ocupado, a partir de la segunda guerra mundial y del trabajo de organismos internacionales como la UNESCO de cuestiones como tipografía, diseño, vocabulario, estructura, coherencia del texto, etc.

Por otro lado el impacto del libro de texto sobre el trabajo de los estudiantes (dentro y fuera de la escuela) es evidente, por lo que un modelo de análisis comprensivo debe analizar sus implicaciones metodológicas. No han faltado críticas en la literatura a la estandarización de los procesos de aprendizaje, al hecho de que promueve una metodología básicamente individualista y basada en la realización de tareas mecánicas y simples o a la secuencia de tareas repetitiva que impone en las aulas: la explicación de la profesora o profesor del tema siguiendo el contenido del libro, realización de las actividades por parte de los estudiantes y posterior corrección en el aula (Parcerisa, 2009). Es necesario analizar la adaptabilidad de las actividades a las características de los estudiantes y al contexto social y cultural en el que se va a aplicar. Especial atención requiere el análisis de si las tareas propuestas fomentan un aprendizaje individualizado o grupal, promueven formas de expresión alternativas al lápiz y al papel, fomentan actividades dirigidas a la interacción de actividades manuales e intelectuales, potencian la búsqueda de fuentes de información alternativas al propio material, etc. (Martínez Bonafé, 1992). Es necesario también analizar el tipo de criterios y estrategias de evaluación propuestos o implícitos en la metodología propuesta.

En la medida en que el libro de texto también es un material de uso de los profesores debemos analizarlo en función de su potencialidad para favorecer la reflexión curricular en las aulas. Un buen material curricular debe justificar las opciones didácticas que lo avalan, debe ser un material coherente, experimentado, flexible (para que otros puedan adaptarlo a su práctica de una forma creativa y no mecánica), debe incluir datos para la reflexión y promover estrategias de coordinación docente innovadoras, que contribuyan a superar el aislamiento docente. No es muy difícil concluir que los libros de texto están alejados de cumplir los criterios anteriormente señalados: en ellos nunca se explican los motivos de las elecciones que se realizan, ni acostumbran a informar de dónde provienen sus fuentes de información.

Las implicaciones que los libros de texto tienen en la profesionalidad docente no sólo tienen que ver con las características del propio material, sino también con el uso que los profesores y profesoras hacen de los mismos. Las investigaciones desarrolladas en este campo (Area, 2009; Mazaikiene y otros, 2011) nos muestran cómo el libro de texto controla en buena medida lo que sucede en el aula, siendo el principal recurso de instrucción, pero el uso que los profesores/as hacen de los libros de texto no siempre reproduce las formas imaginadas por los autores cuando escribieron el material 
pudiendo hacerse un uso flexible de los mismos (Carmen y Jiménez, 2010). No todos los profesores utilizan el libro de texto de una forma mecánica y es muy probable que una minoría siga el texto página a página. Sin embargo este hecho no nos debería hacer olvidar el papel privilegiado que ocupa entre las prescripciones curriculares y la práctica del aula, lo que no está de hecho favoreciendo el desarrollo profesional ni la innovación educativa, aunque admitamos que tampoco debemos ver a los profesores y profesoras como sujetos pasivos en su utilización.

El libro de texto selecciona y representa el universo científico y cultural que se pretende enseñar a los estudiantes reflejando los valores, estereotipos e ideologías de una determinada sociedad. A nuestro modelo de análisis debemos añadir, pues, criterios que nos permitan juzgar la selección cultural que todo libro de texto realiza, así como el mundo de los valores, estereotipos e ideologías que transmiten tanto en el texto como en las imágenes, tarea a la que ha estado dedicada gran parte de la investigación sobre libros de texto desde el trabajo pionero de Anyon (1979) acerca de la representación de la clase obrera en los libros de historia. Los estudios ideológicos de los libros de texto nos han mostrado cómo en la selección cultural realizada prima la cultura académica frente a la popular, se nos ofrece una imagen de la ciencia como algo acabado en la que no existe la controversia, a menudo no se presentan los conocimientos actualizados pero, sobre todo, transmiten de una forma no siempre evidente elementos racistas, sexistas, etnocéntricos, colonialistas, homófobos y, en general, discriminatorios con grupos sociales minoritarios o discriminados (Torres, 1991).

Los editores de libros de texto se han esforzado desde el inicio de este tipo de estudios por incorporar representaciones no sesgadas de las culturas silenciadas (Torres, 1994, 2011) en los libros, fruto en numerosas ocasiones de los debates generados en la opinión pública y de las presiones que autoridades o colectivos sociales han venido ejerciendo desde hace décadas. Sin embargo estos esfuerzos a menudo finalizan con una incorporación meramente superficial y aditiva de este tipo de contenidos. Formalmente se cumple la exigencia pero no se produce una auténtica revisión del conocimiento curricular. Como consecuencia los estudiantes siguen sin poder conocer en profundidad la situación de estos colectivos olvidados y, sobre todo, sin poder analizar las razones que les han colocado en una situación de discriminación (Torres, 2011). Las relaciones entre saber y poder quedan intactas, como muy bien nos han enseñado las perspectivas postcríticas del currículum (Tadeu Da Silva, 2001).

Los métodos utilizados para analizar valores y estereotipos incluyen el análisis de textos e imágenes y es habitual que se centren en algún aspecto concreto como sexismo o racismo. Menos comunes son los trabajos que utilizan una perspectiva más amplia abordando la representación de todos los grupos discriminados. Una de las investigaciones clásicas que utilizó un enfoque más comprensivo fue la realizada en el contexto estadounidense por Sleeter y Grant (1991) analizando la representación de clase social, raza, sexo y discapacidad en libros de las principales materias enseñadas de $1^{\circ}$ a $8^{\circ}$ curso. En la metodología seguida en su trabajo encontramos las estrategias de análisis más comunes en esta tradición: análisis de la imagen, análisis de las antologías en los libros de lectura, análisis de "gente a estudiar", análisis del lenguaje y 
análisis de la narración en ciencias sociales (qué grupo recibe la atención más sostenida) (Sleeter y Grant, 1991: 82-83).

En nuestro contexto son de obligada referencia dentro de esta línea de investigación los trabajos pioneros de Calvo Buezas (1989), de ONGs como Hegoa (Argibay y otros, 1991; Grupo Hegoa, 1996), Sodepaz (Moreno Lorite, 1990) y Ecologistas en Acción (2007), o bien de grupos de profesores como el Grupo Eleuterio Quintanilla (1998, 2006; Castiello, 2002) que han venido denunciando desde hace tiempo los sesgos etnocéntricos, racistas o antiecologistas de nuestros manuales escolares. Así por ejemplo el Grupo Eleuterio Quintanilla (1998) ha demostrado la ausencia de referencias al pueblo gitano en nuestros libros de texto y más recientemente que los libros de texto no ayudan a los adolescentes a aprender de la historia. Del análisis del tratamiento del Holocausto en un total de 42 libros de $4^{\circ}$ de la ESO y $1^{\circ}$ de Bachillerato de Ética, Ciencias Sociales, Historia y Filosofía en el curso 2005-06 de las principales editoriales, concluyen que la mirada histórica relega a un segundo plano una mirada ética o filosófica que permita a los estudiantes extraer lecciones generales sobre la estigmatización de los grupos sociales. Por otra parte la selección de los textos silencia la voz de las víctimas, ofreciendo únicamente la voz de los verdugos (Grupo Eleuterio Quintanilla, 2006). En una línea similar el reciente trabajo de Mayoral y otros (2012) denuncia la visión sesgada de la representación del Islam en los libros de texto en Cataluña.

Desde la denuncia del sexismo son de obligada referencia los trabajos desarrollados por el Instituto de la Mujer (AA.VV. 2000) o por investigadoras pioneras como Marina Subirats que demostraron la abrumadora presencia de personajes masculinos en los libros (Subirats,1993). La investigación realizada por Nieves Blanco en 56 manuales LOGSE de ciencias sociales, lengua y literatura, ciencias naturales, matemáticas y educación física, de $1^{\circ}$ y $2^{\circ}$ de ESO, encontró de nuevo que el $75 \%$ de los personajes eran hombres (Blanco, 2000). En el caso de personas reconocidas por su aportación a la historia, la cifra ascendía al 95\%. Los hombres desarrollaban 344 profesiones distintas y las mujeres sólo 94. Ellos tenían trabajos relacionados con el poder y la creación artística o cultural, mientras que ellas hacían de madres, artistas, diosas o sacerdotisas. El reciente trabajo de Ana López-Navajas (2014) corrobora años más tarde la misma tendencia. En 115 textos escolares de todas las materias de $1^{\circ}$ a $4^{\circ}$ de la E.S.O. se constata de nuevo una muy escasa presencia de mujeres: un $12,8 \%$, lo que revela la falta de consideración social de las mujeres y su práctica exclusión de la visión de mundo que se traslada desde la enseñanza.

Es habitual que las editoriales nieguen la existencia de discriminación intencionada en estas obras, resaltando que dan orientaciones claras a sus autores/as para que tengan en cuenta las cuestiones de género tanto en el texto como en las ilustraciones y es cierto que la situación ha mejorado en los últimos años fruto de la denuncia continuada de numerosos colectivos feministas, asociaciones de profesorado o investigadoras. Sin embargo la discriminación evidente parece haber dado paso a otra más sutil que sigue sin valorar la cultura femenina, la aportación de las mujeres al progreso social, que no ofrece modelos de identificación social femeninos o que sigue sin abordar adecuadamente las cuestiones de género (Ledesma, 2010; Pellejero y Torres, 2011). 
Volviendo a nuestro modelo de análisis, tampoco deberíamos olvidar desde una perspectiva comprensiva las cuestiones de economía cultural y política implicadas en la producción, comercialización y distribución de los libros (Apple, 1989, 1993; Borre Jhonsen, 1996; Pérez Sabater, 2001; Watt, 2007). Desde los años ochenta se empieza a estudiar la cultura y comercio de las editoriales. El papel de los editores es decisivo en la vida de un texto, desde su concepción hasta que llega al pupitre de un alumno, actuando como intermediarios entre las diversas partes del sistema escolar. Desde este tipo de análisis podemos entender por qué son raros los libros de texto que introducen innovaciones, ya que una lógica basada exclusivamente en el beneficio aconseja no introducir excesivas modificaciones y explica que actualmente los libros de texto que compiten entre sí no presenten diferencias significativas. Sus variaciones responden más a cambios obligados por las reformas educativas que a la evolución de la propia dinámica cultural y pedagógica (Martínez Bonafé y Rodríguez Rodríguez, 2010).

Por último no debemos olvidar que sería necesario analizar el uso que los estudiantes hacen de los libros. ¿Cómo influyen los libros de texto en el aprendizaje de los alumnos y alumnas? ¿Cómo los utilizan y los reinterpretan tanto en las aulas como fuera de ellas? ¿Qué es lo que los estudiantes aprenden de ellos? (Dargusch y otros, 2011). Lo que parece claro es que los estudiantes no aprenden a ver el libro de texto como un objeto de investigación, como un mero recurso y mucho menos como algo interpretable.

Todos las dimensiones necesarias para un análisis comprensivo de libros de texto se pueden ver en la Figura 1.

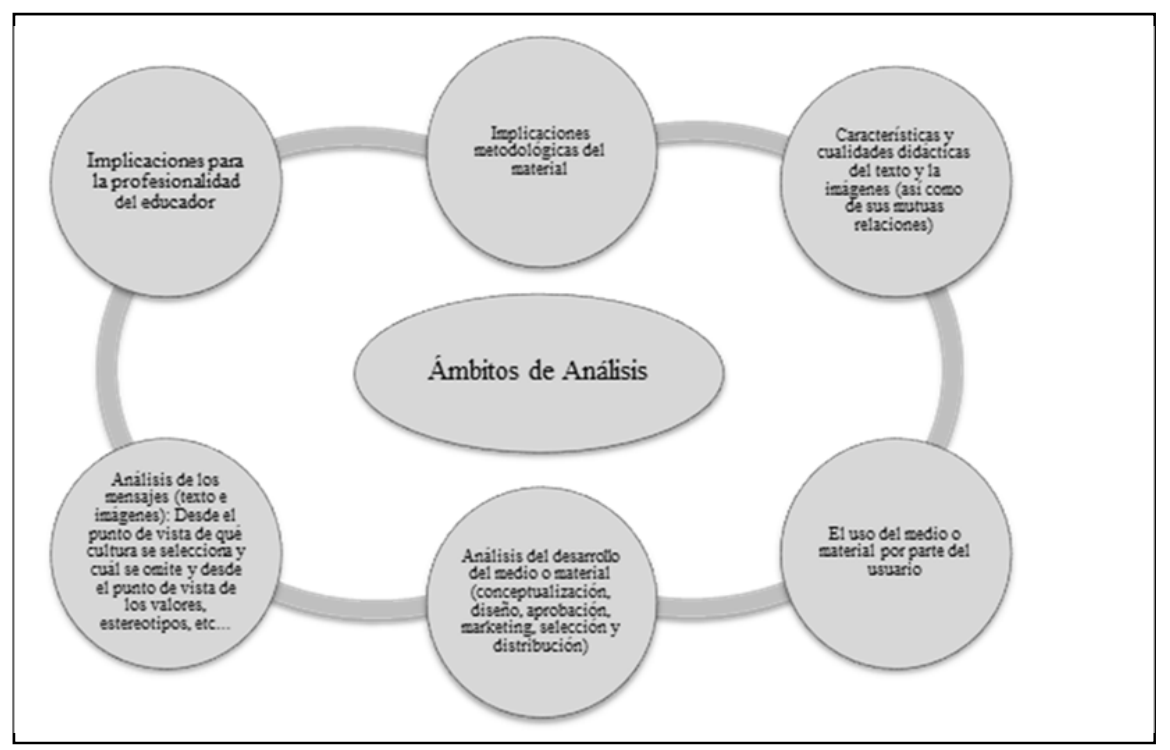

Figura 1: Dimensiones de análisis de libros de texto. 


\section{Una experiencia formativa utilizando el análisis de libros de texto en el Grado de Pedagogía}

\section{Contexto}

Defendemos que el análisis de libros de texto es una práctica didácticamente relevante en ciertas asignaturas de los títulos de Maestro y Pedagogía tales como Didáctica General, Diseño, desarrollo e innovación del currículum o Tecnología Educativa. En nuestro caso hemos realizado esta práctica en la asignatura de segundo semestre del tercer curso del grado de Pedagogía "Análisis y diseño de materiales para la educación y la formación” durante los dos últimos cursos académicos (curso 12-13 y 13-14) en el marco de la implantación de los nuevos estudios de grado del E.E.E.S.

La citada práctica contribuye a desarrollar importantes competencias profesionales de la titulación de Pedagogía como la evaluación y diseño de recursos educativos en diversos contextos o el asesoramiento sobre el uso pedagógico y la integración curricular de materiales ${ }^{1}$.

\section{Desarrollo metodológico de la práctica}

Para la realización de la práctica los estudiantes, de forma grupal, escogen un libro de texto en vigor en nuestra comunidad autónoma. Se les ofrece un guión de análisis basado en las dimensiones que hemos identificado como relevantes para la tarea, incluyendo preguntas abiertas para la reflexión recogiendo lo que la literatura nos ha ido enseñando sobre evaluación de libros de texto (AA.VV. 1996; Blanco, 1994; Castiello, 2002; González García, 2005; González Jiménez y Macías Gómez, 2001; Martínez Bonafé, 1992, 1995; Parcerisa, 1996). Por razones prácticas se eliminan del guión, aunque no de la reflexión, las cuestiones relacionadas con el uso, producción y comercialización de los mismos, imposibles de evaluar a partir exclusivamente del análisis de libros de texto editados.

El guión no se utiliza sólo como una herramienta para orientar el análisis, sino que nos permite ir justificando dimensión por dimensión por qué es necesario analizar ese tipo de cuestiones en un material como el libro de texto y de dónde salen los criterios para interrogarlo, relacionando de esta manera teoría y práctica en la asignatura. La justificación teórica del guión es para nosotros tan importante como la aplicación del mismo.

No entendemos el guión como un instrumento cerrado, sino como una estructura interrogativa que les permita ver lo que no están acostumbrados a ver. Como activos usuarios de libros de texto que han sido durante toda su escolaridad los han "naturalizado" y la gran mayoría de ellos reconocen que nunca los habían cuestionado, por lo que la primera dificultad que nos hemos encontrado al desarrollar la práctica ha sido la de obligarles a verlos desde múltiples perspectivas. En la siguiente tabla se

\footnotetext{
${ }^{1}$ Memoria de Verificación del Grado de Pedagogía de la Universidad de Oviedo.
} 
presentan las dimensiones, principales unidades de análisis e interrogantes del guión utilizado (Tabla 1).

\section{ANÁLISIS DE LOS ASPECTOS FORMALES:}

- Aspectos estéticos, formato estructurado o flexible, tipografía, índice, instrucciones de uso, resúmenes, introducciones, adecuación del lenguaje utilizado a los destinatarios, interacción entre el lenguaje verbal y la imagen, calidad didáctica de las ilustraciones, estrategias utilizadas para facilitar la lectura, etcétera.

\section{ANÁLISIS METODOLÓGICO:}

- Estructura y estilo de las tareas: ¿Se resuelven con el propio material o es necesario acudir a otras fuentes? ¿Son tareas de diferente grado de complejidad? ¿Existen tareas que se deban resolver en largos periodos de tiempo? ¿Mayoritariamente individuales o colectivas? ¿Homogéneas/heterogéneas? ¿Qué tipo de aprendizaje promueven? ¿La secuencia de tareas se repite de unidad a unidad? ¿Promueven formas de expresión variadas y alternativas al lápiz y al papel? ¿El libro sugiere agrupamientos flexibles?

- Evaluación: ¿Qué criterios y procedimientos de evaluación promueve el libro de texto?

3. ANÁLISIS DE MENSAJES:

- Análisis del contenido: actualización, relación con problemas sociales o de la vida cotidiana del alumnado, diversidad de fuentes utilizadas, presencia o ausencia de saberes populares, enfoque estrictamente disciplinar o globalizador, presencia o ausencia de temas transversales, presencia o no de temas conflictivos en la propia comunidad científica. ¿Se justifica el por qué de la selección del conocimiento que se ha llevado a cabo? ¿Se incluyen referencias a la construcción histórica del conocimiento?

- Análisis de valores, estereotipos, etc., en el texto y en las imágenes: Análisis de personajes por sexo, raza, clase social, grupo de edad y discapacidad teniendo en cuenta el protagonismo que se les otorga y el contexto en el que se los presenta. ¿Qué explicación se ofrece de las relaciones de desigualdad entre grupos? Análisis del lenguaje para verificar su posible uso cargado de estereotipos. ¿Se evitan imágenes catastróficas o idílicas en relación a los grupos minoritarios o discriminados?

4. IMPLICACIONES PARA LA PROFESIONALIDAD DOCENTE:

- ¿ ¿Se explicitan las justificaciones de sus opciones y el proceso de toma de decisiones seguido? ¿Es un material didácticamente coherente? ¿Está experimentado? ¿Se incluyen recursos complementarios al propio libro tanto para profesorado como para alumnado? ¿Se incluye un libro del profesor/a con una programación completamente diseñada? ¿Sugiere en algún momento que los profesores/as preparen actividades complementarias? ¿Es un material diseñado para ser usado de una determinada forma? ¿Prevé posibles dificultades en su puesta en práctica? ¿Sugiere en algún momento estrategias de coordinación docente?

\section{OTRAS VALORACIONES:}

- Compara la propuesta curricular que hace el libro de texto con el currículum oficial. Compara el libro que has elegido con su equivalente en otra comunidad autónoma. Compara tu libro con otro de otra editorial para el mismo curso y materia. Compara tu libro con versiones digitales de la misma editorial.

6. VALORACIÓN FINAL y PROPUESTAS DE MEJORA.

Tabla 1. Guión utilizado en el desarrollo de la práctica. Principales líneas de análisis en cada dimensión. 
La práctica se realiza de forma grupal y durante estos dos cursos académicos se han analizado un total de 30 libros de texto diferentes ${ }^{2}$ de Educación Primaria, E.S.O y Bachillerato en vigor en nuestra comunidad autónoma implicando a un total de 120 estudiantes. Se les recomienda que escojan libros de texto del ámbito de las ciencias sociales/humanidades, ya que son los más adecuados para la realización de análisis de mensajes (valores, estereotipos, protagonistas de las historias, etc.). El resumen de datos relativos a los libros analizados puede consultarse en la siguiente tabla (Tabla 2).

\begin{tabular}{|c|c|c|c|}
\hline ÁREAS DE CONOCIMIENTO & PRIMARIA & E.S.O. & BACHILLERATO \\
\hline $\begin{array}{l}\text { Conocimiento del Medio Social y } \\
\text { Natural }\end{array}$ & 10 & & \\
\hline $\begin{array}{c}\text { Educación para la Ciudadanía y los } \\
\text { Derechos Humanos } \\
\end{array}$ & 2 & 6 & \\
\hline Educación ético- cívica & & 4 & \\
\hline $\begin{array}{c}\text { Ciencias Sociales, Geografía e } \\
\text { Historia } \\
\end{array}$ & & 5 & \\
\hline Cultura Clásica & & 1 & \\
\hline Filosofía y Ciudadanía & & & 2 \\
\hline $\begin{array}{l}\text { TOTAL LIBROS DIFERENTES } \\
\text { ANALIZADOS }\end{array}$ & 12 & 16 & 2 \\
\hline EDITORIALES & $\begin{array}{c}\text { SM, Santillana, } \\
\text { Vicens-Vives y } \\
\text { Anaya. }\end{array}$ & $\begin{array}{l}\text { Pearson/Alhamb } \\
\text { ra, SM, } \\
\text { Santillana, } \\
\text { McGraw-Hill, } \\
\text { Vicens - Vives, } \\
\text { Edebé, } \\
\text { Ediciones } \\
\text { Serbal, Everest, } \\
\text { Editex y } \\
\text { Oxford. }\end{array}$ & $\begin{array}{l}\text { MacGraw-Hill y } \\
\text { Santillana. }\end{array}$ \\
\hline
\end{tabular}

Tabla 2. Libros analizados en los cursos académicos 12-13 y 13-14: etapas educativas, áreas de conocimiento y editoriales.

\footnotetext{
${ }^{2}$ En realidad se han realizado 35 trabajos grupales, pero 5 de los libros analizados se repitieron de un curso académico a otro.
} 


\section{Análisis cualitativo de los informes desarrollados por los estudiantes}

Una vez desarrollada la práctica durante dos cursos académicos hemos realizado un análisis cualitativo de los informes finales presentados por los estudiantes (un total de treinta). La información se ha categorizado siguiendo las dimensiones presentes en el guión de la práctica (análisis de los aspectos formales, metodología subyacente, análisis de mensajes, implicaciones para la profesionalidad docente y otras valoraciones) y clasificando los hallazgos como fortalezas o debilidades de los libros de texto, a partir de un vaciado realizado primero de forma independiente por los dos profesores de la asignatura y que luego se ha puesto en común.

Las dificultades encontradas por los estudiantes en la realización de la práctica se han identificado a partir de las valoraciones individuales que se les pedía a los estudiantes al finalizar el trabajo, del análisis de las puestas en común que se hicieron en el aula y de la reflexión conjunta de los dos profesores de la asignatura. El trabajo cooperativo en la impartición de asignaturas universitarias puede sin duda ayudarnos a desarrollar prácticas reflexivas necesarias en un contexto de burocratización progresiva de la docencia universitaria.

\section{Análisis de los aspectos formales}

En general las valoraciones que nuestros estudiantes hacen de los libros de texto son bastantes positivas en lo que se refiere a aspectos estéticos o estructura de los libros, señalando en muchas ocasiones (en un $73 \%$ del total de casos analizados) ${ }^{3}$ que se ha producido una notable mejoría de estos aspectos en los últimos años. Las principales críticas recaen en la escasa interacción entre lenguaje verbal e imagen y en la escasa calidad didáctica de las ilustraciones.

\section{Análisis metodológico}

En este apartado la consistencia de las valoraciones es grande. Concluyen mayoritariamente que predominan de forma evidente las actividades individuales frente a las grupales (93\%), que se repiten el tipo y secuencia de tareas de unos temas a otros (90\%) y que predominan actividades de memoria, comprensión y rutina frente a las de análisis, descubrimiento u opinión (83\%). Incluso aquellas editoriales que incluyen actividades grupales o de más complejidad las sitúan siempre al final de los temas o en los márgenes del libro transmitiendo claramente el mensaje de que tienen un papel secundario o, en el mejor de los casos, complementario. Especialmente los grupos que trabajaron con los libros de primaria señalaron el bajísimo grado de ambigüedad de las tareas. El número excesivo de actividades ha sido también una conclusión mayoritaria (86\%). Los libros mejor valorados con diferencia en cuanto a la complejidad y variedad de las tareas que proponen son, sin lugar a dudas, los de

\footnotetext{
${ }^{3}$ Los porcentajes harán referencia, a partir de este momento, al número de informes que coinciden en una valoración común del total de 30 informes analizados.
} 
Educación para la Ciudadanía, seguramente porque al tratarse de una asignatura "transversal” y con poca historia curricular permite planteamientos metodológicos más arriesgados.

Análisis de mensajes.

En cuanto al análisis del contenido informativo incluido en los libros, ésta ha sido una de las dimensiones sin duda más difíciles de la aplicación del guión. Los estudiantes han encontrado serias dificultades para entender incluso qué se pretendía analizar ya que están muy habituados como aprendices a no cuestionar la naturaleza del conocimiento académico que se les imparte. Recordar los planteamientos de las teorías postcríticas del currículum nos ha sido útil y, salvo en contadas ocasiones, han identificado una visión excesivamente disciplinar y ausente de controversia en el conocimiento escolar formateado en los libros de texto. La cantidad de temas y de información presente en los manuales les ha parecido de forma casi unánime excesiva (93\%).

El análisis de valores y estereotipos en el texto y en las imágenes ha sido sin duda una de las dimensiones de análisis más sugerente. Tenemos que decir que los resultados han sido muy dispares dependiendo en este caso del área de conocimiento (los libros de ciudadanía suelen cuidar estos aspectos) y de la editorial. Lo más llamativo de sus análisis ha sido la uniformidad con la que todos los grupos han denunciado la escasa o nula presencia de la discapacidad en nuestros libros de texto (93\%), hecho que Hodkinson (2014) ha constatado que también sucede en los materiales en soportes electrónicos utilizados en las aulas. En su mayoría, también han detectado una visión etnocéntrica especialmente en las imágenes (66\%). Muchos grupos han percibido también un esfuerzo editorial por representar a las mujeres en igualdad de condiciones que los hombres en las imágenes (83\% de los grupos), mientras que valoran como insuficiente la historia y perspectiva de las mujeres en la narración.

\section{Implicaciones para la profesionalidad docente}

En este caso disponer o no del libro del profesor permitía análisis diferenciados. Una de las mayores sorpresas que se han llevado los estudiantes ha sido comprobar que los libros para el profesorado pueden llegar a incluir, incluso, las preguntas a plantear en el aula con las respuestas "correctas" sobre un determinado tema. Han señalado también que los libros incluyen cada vez más recursos adicionales como enlaces a páginas web o a recursos digitales de las editoriales.

Una de las cosas más llamativas para ellos fue comprobar cómo los intentos de los libros de texto por justificar que estaban cumpliendo con el nuevo discurso curricular de las competencias les llevaba a veces a plantear en sus primeras páginas las relaciones entre sus contenidos y actividades y las competencias curriculares de formas incomprensibles, arbitrarias o didácticamente incorrectas. 


\section{Otras valoraciones}

En este apartado han valorado que la presencia de Asturias en los libros de conocimiento del medio y/o sociales es escasa o, en todo caso, se presenta en temas específicos del libro sin que se integre adecuadamente a lo largo de todos los contenidos del curso.

La comparación del libro con las versiones digitales del mismo es un elemento de reflexión muy importante en este momento en el que las editoriales están optando por digitalizar muchos de sus contenidos. Tanto en el gran grupo como en pequeño grupo se visitaron las propuestas digitales de las editoriales surgiendo una pregunta clave a la que creemos debemos dedicar más tiempo en próximos cursos: ¿qué aportan realmente de nuevo las versiones digitales? La comparación entre editoriales es relevante para poder "visibilizar" la necesaria interpretación que del currículum oficial hacen las mismas. Uno de los temas que surgió en casi todos los grupos durante el curso académico 13-14, sin duda por el impacto de la crisis, fue el desorbitado precio de los libros de texto lo que nos llevó a analizar los debates y propuestas que se están planteando en relación a las políticas de gratuidad, bancos de libros, reivindicación del mantenimiento de los libros a pesar de la implantación de la LOMCE o libros de texto diseñados y colgados gratuitamente por profesores y profesoras en la red.

\section{Discusión de resultados y conclusiones}

En cuanto al sentido de introducir esta práctica en la formación universitaria, esta experiencia nos permite afirmar que el análisis de libros de texto es una actividad formativa motivadora para los y las estudiantes, a la vez que permite poner en juego muchos de los conocimientos y competencias curriculares necesarios para un futuro profesional de la educación.

Los y las estudiantes han aprendido que existen diferencias editoriales en la interpretación del currículum oficial y en el abordaje de ciertos temas conflictivos, que la disciplinariedad no favorece el diseño de materiales innovadores o que el aumento de acceso a contenidos y recursos digitales y on-line no siempre aporta posibilidades realmente innovadoras. También han aprendido que queda mucho camino por recorrer en el diseño de buenos libros de texto y han realizado algunas propuestas de mejora:

o Hay que mejorar la utilización didáctica de las imágenes.

o Es necesario evitar el predominio de una metodología básicamente individualista basada en encontrar (normalmente en el propio libro) la respuesta correcta.

o Necesidad de problematizar los conocimientos que se ofrecen, sin huir de la controversia.

o Reducir el excesivo número de temas y actividades, ya que puede traducirse en una gran presión curricular sobre el profesorado para "terminar" el libro de texto. 
o Visibilizar ciertos colectivos ausentes (especialmente las personas con discapacidad) y evitar visiones estereotipadas de determinados colectivos (personas no europeas o procedentes de países pobres).

o Es necesario seguir revisando cómo se representa la historia y perspectiva de las mujeres en la narración, sin dar por supuesto que su mayor presencia en las imágenes es suficiente.

Los estudiantes han tenido que poner en práctica capacidades de análisis utilizando criterios de calidad didáctica útiles para juzgar y diseñar todo tipo de materiales (no sólo aquellos en soporte papel). Se han tenido que enfrentar a interrogantes teóricos muy adecuados para cualquier asignatura del ámbito didáctico (¿quién toma las decisiones en el diseño/desarrollo del currículum? ¿qué caracteriza a un material innovador?) y han aprendido a cuestionar los mensajes transmitidos en los libros de texto a través del análisis no sólo de su contenido informativo, sino también de los posibles valores o estereotipos que transmiten.

Las valoraciones individuales de la práctica que han hecho los estudiantes han sido muy positivas, aunque manifiestan que no ha sido un trabajo fácil y que, en general, los libros de texto son muy similares a los que ellos utilizaron en su época de escolaridad:

"Me ha parecido muy interesante esta práctica, pues me ha permitido ver un elemento con el que he estudiado durante toda la vida desde otra perspectiva, ofreciéndome la posibilidad de ver todos esos valores, estereotipos, etc, que se ocultan detrás de ellos.”

Nosotros también hemos aprendido de la reflexión en la práctica. Como aspectos a mejorar para el futuro, nos planteamos ampliar el abanico de libros de texto, explorar más el análisis de las versiones digitales y la comparativa entre comunidades, así como establecer relaciones entre lo aprendido en esta práctica y lo trabajado en otras materias: ¿por qué no realizar un análisis de la evolución histórica de los libros de texto en asignaturas de Historia del Currículum presentes en nuestra titulación y en las que participamos?; ¿por qué no recuperar lo aprendido para juzgar otro tipo de materiales en formatos digitales en asignaturas como "Escenarios virtuales para la educación y la formación” en la que también participamos?

También nos planteamos en el futuro ampliar las técnicas de reflexión en la práctica utilizadas incluyendo observación por parte de un evaluador externo (un "amigo crítico") que nos permita triangular puntos de vista, así como realizar grupos de discusión con estudiantes para conocer mejor lo que han aprendido (más allá del análisis de los informes escritos) y poder escuchar sus propuestas de mejora de la actividad.

Como futuros pedagogas y pedagogos tienen que conocer el funcionamiento escolar y las estrategias del asesoramiento e innovación escolar, pueden trabajar en el ámbito de las editoriales y tendrán que seleccionar o diseñar materiales para muy diversos contextos educativos y formativos. Para todo ello el análisis de libros de texto es una práctica formativa relevante y necesaria. 


\section{Referencias bibliográficas}

AA.VV. (1996). Análisis de recursos educativos desde la perspectiva no sexista. Barcelona: Laertes.

AA.VV. (2000). La transmisión de los modelos femenino y masculino en los libros de la enseñanza obligatoria. Madrid: Instituto de la mujer

ANELE (Asociación Nacional de Editores de Libros y Material de Enseñanza) (2013). Informe sobre la edición de libros de texto en España. Recuperado de http://www.anele.org/pdf/Sector\%20de\%20Libros\%20de\%20Texto\%202013.pdf

ANYON, J. (1979). Ideology and United States History Textbooks. Harvard Educational Review, 49 (3), 361-368.

APPLE, M. W. (1989). Maestros y textos. Una economía política de las relaciones de clase y de sexo en educación. Barcelona: Paidós/M.E.C.

APPLE, M.W. (1993). El libro de texto y la política cultural. Revista de Educación, 301, 109-126.

AREA, M. (2009). Introducción a la tecnología educativa. Creative Commons: Universidad de La Laguna. Recuperado de https://manarea.webs.ull.es/wpcontent/uploads/2010/06/ebookte.pdf

ARGIBAY, M. y otros (1991). La cara oculta de los textos escolares. Bilbao: UPV/EHU-Hegoa.

BEAS, M. (1999). Los libros de texto y las Comunidades Autónomas: una pesada Torre de Babel. Revista Complutense de Educación, 10, (2), 29-52.

BEAS, M. (Ed.). (2013). Ciudadanías e identidades en los manuales escolares (19702012). Sevilla: Díada Editora y Junta de Andalucía.

BLANCO, N. (1994). Materiales curriculares: los libros de texto. En ANGULO, F. y BLANCO, N. (Eds.), Teoría y desarrollo del curriculum (pp. 263-280). Málaga: Aljibe.

BLANCO, N. (2000). Mujeres y hombres para el siglo XXI. El sexismo en los libros de texto. En M. A. SANTOS GUERRA (Ed.), El harén pedagógico. Perspectiva de género en la organización escolar (pp. 119-146). Barcelona: Graó.

BLANCO, N. (2001). La dimensión ideológica de los libros de texto. Kikirikí, 61, 5056.

BLANCO, N. (2008). Los saberes de las mujeres y la transmisión cultural en los materiales curriculares. Investigación en la escuela, 65, 11-22.

BORRE JOHNSEN, E. (1996). Libros de texto en el calidoscopio. Estudio crítico de la literatura y la investigación sobre los textos escolares. Barcelona: PomaresCorredor

CALVO BUEZAS, T. (1989). Los racistas son los otros. Gitanos, minorías y derechos humanos en los textos escolares. Madrid: Popular. 
CARMEN, L.M. Del y JIMÉNEZ, P. (2010) Los libros de texto: un recurso flexible. Alambique: Didáctica de las CC. Experimentales, XVII (66), 48-55.

CASTIELLO, J.M. (2002). Los desafíos de la educación intercultural: migraciones y currículum. Tesis doctoral. Universidad de Oviedo.

DARGUSCH, J. PERSAUD, N. y HORSLEY, M. (2011). Judging the quality of educational materials - a research Project on student voice. IARTEM e-Journal, 4 (2), 45-62. Recuperado de www.iartem.org

ECOLOGISTAS EN ACCIÓN (2007). Educación y Ecología. El currículum oculto antiecológico de los libros de texto. Madrid: Editorial Popular.

ESCOLANO, A. (Ed.). (1997). Historia ilustrada del libro escolar en España. Del Antiguo Régimen a la Segunda República. Madrid: Fundación Germán Sánchez Ruipérez.

ESCOLANO, A. (1998). La segunda generación de manuales escolares. En ESCOLANO, A. (Ed.), Historia ilustrada del libro escolar en España. De la posguerra a la reforma educativa. (19-49) Madrid: Fundación Germán Sánchez Ruipérez.

FIGUEIREDO, T.M., DE LIMA, D.C., SANTIAGO, L., RODRÍGUEZ, J. y KNUDSEN, S. (Eds.) (2013). Retos para superar las desigualdades sociales: el papel de los libros de texto y los medios didácticos. Curitiba, Brasil: NPPD/UFPR e IARTEM. Recuperado de http://iartemblog.wordpress.com/publications/

GIMENO, J. (2012) (2 $2^{\text {a }}$ Ed.). Grandeza y miseria del libro de texto. En GIMENO, J. FEITO, R. PERRENOUD, Ph. y CLEMENTE, M., Diseño. Desarrollo $e$ innovación del currículum. (pp. 113-118). Madrid: Morata.

GONZÁLEZ GARCÍA, E. (2005). Del uso y abuso de los libros de texto: criterios de selección. Revista de Educación de la Universidad de Granada, 18, 269-281.

GONZÁLEZ JIMÉNEZ, F.E. y MACÍAS GÓMEZ, E. (2001). Criterios para valorar materiales curriculares: una propuesta de elaboración referida al rendimiento escolar. Revista Complutense de Educación, 12 (1), 179-212.

GONZÁLEZ, E. y MONTERO, I. (2013). Libros de texto y mapa editorial: análisis de la ciudadanía, las identidades y la cultura política. En BEAS, M. (Ed.), Ciudadanías e identidades en los manuales escolares (1970-2012). (pp. 89-115). Sevilla: Díada Editora y Junta de Andalucía.

GRUPO ELEUTERIO QUINTANILLA (1998). Libros de texto y diversidad cultural. Madrid: Talasa.

GRUPO ELEUTERIO QUINTANILLA (2006). Pensad que esto ha sucedido. Donostia: Tercera Prensa.

GRUPO HEGOA (1996). ¿¿ué dicen los textos escolares? Cuadernos de Pedagogía, 215, 13-15. 
HODKINSON, A. (2014). "Safe Spaces"- Electronic media, the internet, and the representation of disability. IARTEM e-jounal, 6 (1), 1-20. Recuperado de www.iartem.org

LEDESMA, N. (2010). Coeducación y materiales curriculares en la Red. En AA.VV (Ed.), Materiales curriculares, integración de las TIC y atención a la diversidad (pp. 42-81). Madrid: Ministerio de Educación.

LÓPEZ-NAVAJAS, A. (2014). Análisis de la ausencia de las mujeres en los manuales de la E.S.O: una genealogía de conocimiento ocultada. Revista de Educación, 363, 282-308.

MARTÍNEZ BONAFÉ, J. (1992). Cómo analizar los materiales. Cuadernos de Pedagogía, 203, 14-18.

MARTÍNEZ BONAFÉ, J. (1995). Interrogando al material curricular (guión para el análisis y la elaboración de materiales para el desarrollo del curriculum. En MINGUEZ, J. G. y BEAS, M. (Eds.), Libros de texto y construcción de materiales curriculares (pp. 221-245). Armilla (Granada): Proyecto Sur de Ediciones.

MARTÍNEZ BONAFÉ, J. (2002). Políticas del libro de texto escolar. Madrid: Morata.

MARTÍNEZ BONAFÉ, J. (2007). El libro de texto ¿un recurso para la innovación educativa? Aula de innovación educativa, 165, 12-14.

MARTÍNEZ BONAFÉ, J. (2008). Los libros de texto como práctica discursiva. Revista de la asociación de sociología de la educación (RASE), 1(1), 62-73.

MARTÍNEZ BONAFÉ, J., y RODRÍGUEZ RODRÍGUEZ, J. (2010). El currículum y el libro de texto. Una dialéctica siempre abierta. En GIMENO SACRISTÁN, J. (Ed.), Saberes e incertidumbres sobre el currículum (pp. 246-268). Madrid: Morata.

MAYORAL, D. MOLINA, F. y SAMPER, LL. (2012) ¿Islamofobia o currículo nulo? La representación del Islam, las culturas musulmanas y los inmigrantes musulmanes en los libros de texto de Cataluña. Revista de Educación, 357 (Enero-Abril), 257279.

MAZAIKIENE, N. HORSLEY, M. y KUNDSEN, S. (Eds.). (2011). Representation of otherness. 11th. International Conference on Textbooks and educational Media. Kaunas, Lithuania: IARTEM. Recuperado de http://iartemblog.wordpress.com/publications/

MORENO LORITE, C. (1990). ¿Racismo en las imágenes? Un método para el análisis de imágenes fotográficas. Madrid: SODEPAZ.

PARCERISA, A. (1996). Materiales curriculares. Cómo elaborarlos, seleccionarlos. Barcelona: Graó.

PARCERISA, A. (2009). Para aprender no siempre el libro de texto es la mejor opción. Padres y maestros, 322, 15-19. 
PELLEJERO, L. y TORRES, B. (2011). La educación de la sexualidad: el sexo y el género en los libros de texto de educación primaria. Revista de Educación, 354 (Enero-Abril), 399-427.

PÉREZ SABATER, T. (2001). El mercado editorial: producción y comercialización de los libros de texto. Kikirikí, 61, 30-38.

PUELLES, M. (2000). Los manuales escolares: un nuevo campo de conocimiento. Historia de la Educación. Revista Interuniversitaria, 19, 5-12.

RODRÍGUEZ, J. HORSLEY, M. y KNUDSEN, S. (Eds.). (2009). Local, national and transnational identities in textbooks and educational media. 10TH International Conference on textbooks and educational Media. Santiago, Spain: Wendy Ward and IARTEM. Recuperado de http://iartemblog.wordpress.com/publications/

SELANDER, S. (1995). Análisis del texto pedagógico. En MINGUEZ, J.G. y BEAS, M. (1995), Libro de texto y construcción de materiales curriculares. (pp.131-162) Armilla (Granada): Proyecto Sur de Ediciones.

SLEETER, Ch. E. y GRANT, C. (1991). Race, Gender, and Disability in current textbooks. En APPLE, M. W. y CHRISTIAN-SMITH, L. K. (Eds.), The politics of the textbook. (pp. 78-110) New York: Routledge.

SUBIRATS, M. (Coord.). (1993). El sexismo en los libros de texto: análisis y propuesta de un sistema de indicadores. Madrid: Ministerio de Asuntos SocialesInstituto de la Mujer.

TADEU DA SILVA, T. (2001) Espacios de identidad. Barcelona: Octaedro.

TERRA, L. (2014). New histories for a new state: a study of history textbook content in Northern Ireland. Journal of Curriculum Studies, 46(2), 225-248.

TORRES, J. (1991). La reproducción cultural y la cultura en los textos escolares. En TORRES, J. (Eds.), El curriculum oculto (pp. 98-112). Madrid: Morata.

TORRES, J. (1994). Globalización e interdisciplinariedad: el curriculum integrado. Madrid: Morata.

TORRES, J. (1995). Algunas objeciones. Cuadernos de Pedagogía, 235, 68-69.

TORRES, J. (2011). La justicia curricular. Madrid: Morata

WATT, M. G. (2007). Research on the Textbook Publishing Industry in the United States of America, Iartem e-Journal, 1 (1). Recuperado de www.iartem.org 


\section{Correspondencia con los autores}

Gloria BRAGA BLANCO

Dpto. Ciencias de la Educación - Área de Didáctica y Organización Escolar Facultad de Formación del Profesorado y Educación.

Universidad de Oviedo

C/Aniceto Sela, s/n (Despacho 310)

33005 - Oviedo - Asturias

e-mail: gyoya@uniovi.es

José Luis BELVER DOMÍNGUEZ

Dpto. Ciencias de la Educación - Área de Didáctica y Organización Escolar Facultad de Formación del Profesorado y Educación.

Universidad de Oviedo

C/Aniceto Sela, s/n (Despacho 326)

33005 - Oviedo - Asturias

e-mail: belverjose@uniovi.es 